\title{
FORMAÇÃO DE MUDAS DE MARACUJAZEIRO “AMARELO” SOB NÍVEIS DE SOMBREAMENTO EM JI-PARANÁ/RO
}

\author{
Formation of yellow passion fruit seedlings under diferent shading treatments in Ji-Paraná/RO
}

\author{
Fábio Zanella ${ }^{1}$, Regiani Soncela², Ana Lúcia da Silva Lima ${ }^{3}$
}

\begin{abstract}
RESUMO
A utilização de sombreamento é uma importante técnica na formação de mudas de maracujá. O grau de sombreamento pode afetar diretamente o crescimento das mudas e a posterior formação do pomar. Com o presente trabalho, objetivou-se avaliar o crescimento e os teores de pigmentos fotossintéticos em mudas de maracujazeiro "amarelo" (Passiflora edulis Sims f. flavicarpa Deg.) formadas em diferentes níveis de sombreamento. Foram testados quatro tratamentos de sombreamento: $0 \% ; 30 \% ; 50 \%$ e $80 \%$. Cada tratamento constou de cinco repetições dispostas em delineamento inteiramente casualizado. Após 90 dias da semeadura foram realizadas análises quanto ao crescimento e teor de pigmentos fotossintéticos. Em relação às análises de crescimento, constatou-se que a exposição a pleno sol foi prejudicial às mudas. Os níveis de sombreamento de $50 \%$ e $80 \%$ foram os mais favoráveis ao crescimento das mudas. Houve uma redução na relação clorofila $a / b$ e um aumento dos teores de clorofila total e carotenóides totais com o aumento do sombreamento.
\end{abstract}

Termos para indexação: Passiflora edulis, crescimento, clorofila, propagação.

\begin{abstract}
The shading is an important technique used to the formation of passion fruit seedlings. Thus, the shadow intensity can directly affect the growth of the seedlings and the further formation of the orchard. The present work aimed at evaluating the growth and the photosynthetic pigments content in yellow passion fruit seedlings (Passiflora edulis Sims f. flavicarpa Deg.) grown under different shading levels. Four shading treatments were used: $0 \% ; 30 \% ; 50 \%$ and $80 \%$, with five replications each one in a complete randomized design. After 90 days of the sowing the growth and the photosynthetic pigments concentration were analyzed. The seedlings growth was impaired under full sunshine. The most favorable shading treatments for the seedlings growth were $50 \%$ and $80 \%$. The chlorophyll $a / b$ ratio decreased and the total concentration of chlorophyll and carotenoids increased with the increase of the shading.
\end{abstract}

Index terms: Passiflora edulis, growth, chlorophyll, propagation.

(Recebido para publicação em 21 de dezembro de 2005 e aprovado em 21 de março de 2006)

\section{INTRODUÇÃO}

O maracujá-amarelo (Passiflora edulis Sims f. flavicarpa Deg.) tornou-se uma espécie de importância significativa no agronegócio de frutas tropicais. Como reflexo, houve um grande interesse dos produtores por informações técnicas sobre a obtenção de mudas de boa qualidade (MELETTI, 2000). A formação de mudas em viveiro é uma prática muito empregada na cultura do maracujá. A utilização de viveiros pressupõe um sombreamento das plantas por um determinado período que antecede o transplante para o campo (MELETTI, 1994).

Entre os diversos componentes do ambiente, a luz é primordial para o crescimento das plantas, não só por fornecer energia para a fotossíntese, mas, também, por fornecer sinais que regulam seu desenvolvimento por meio de receptores de luz sensíveis a diferentes intensidades, qualidade espectral e estado de polarização. Dessa forma, modificações nos níveis de luminosidade aos quais uma espécie está adaptada podem condicionar diferentes respostas fisiológicas em suas características bioquímicas, anatômicas e de crescimento (ATROCH et al., 2001).

Alguns estudos têm evidenciado a plasticidade fisiológica de espécies vegetais em relação à radiação fotossintéticamente ativa disponível por meio de avaliações de crescimento inicial em relação a diferentes níveis de sombreamento (ALMEIDA et al., 2005). Segundo Paiva et al. (2003), mudas de cafeeiro crescendo sob um sombreamento de $50 \%$ apresentam um maior crescimento vegetativo em relação às mudas formadas em sombreamentos de $30 \%$ e 90 $\%$ e em pleno sol. Para a espécie arbórea pata-de-vaca (Bauhinia forficata Link.), verificou-se que o tratamento de $30 \%$ de sombreamento mostrou-se o mais indicado para o crescimento inicial dessas plantas (ATROCH et al., 2001).

${ }^{1}$ Engenheiro Agrônomo, D.Sc., Universidade Luterana do Brasil - Centro Universitário Luterano de Ji-Paraná - CEULJI/ULBRA - Cx. P. 271 78961-970 - Ji-Paraná, RO - zanellaf@yahoo.com.br

2 Estudante do curso de Agronomia, Universidade Luterana do Brasil - Centro Universitário Luterano de Ji-Paraná - CEULJI/ULBRA - Cx. P. 271 78961-970 - Ji-Paraná, RO - regianisoncela@zipmail.com.br

${ }^{3}$ Bióloga, D.Sc., Universidade Luterana do Brasil - Centro Universitário Luterano de Ji-Paraná - CEULJI/ULBRA - Cx. P. 271 - $78961-970$ Ji-Paraná, RO - limaals@yahoo.com.br 
Nesse contexto, a adaptação das plantas ao ambiente de luz depende do ajuste de seu aparelho fotossintético, de modo que a luminosidade ambiental seja utilizada de maneira mais eficiente possível, sendo, as respostas dessa adaptação refletidas no crescimento global da planta. Assim, a eficiência do crescimento pode estar relacionada com a habilidade de adaptação das plântulas e as condições de intensidade luminosa do ambiente; freqüentemente as análises do crescimento são utilizadas para indicar o grau de tolerância das diferentes espécies ao sombreamento (FANTI \& PEREZ, 2003).

Várias características são utilizadas para avaliar as respostas de crescimento de plantas à intensidade luminosa. Entre essas, a altura da planta é uma das mais utilizadas, visto que a capacidade em crescer rapidamente em altura quando sombreadas é um mecanismo importante de adaptação das espécies que procuram por uma taxa luminosa maior (ENGEL, 1989). A área foliar é uma característica para se analisar a tolerância à sombra das diferentes espécies, pois ela correlaciona-se diretamente com a área da superfície fotossintetizante útil (ENGEL, 1989).

Um dos fatores ligados à eficiência fotossintética de plantas e, conseqüentemente, ao crescimento e à adaptabilidade a diversos ambientes é o conteúdo de clorofila e carotenóides. De forma geral, a clorofila e os carotenóides tendem a aumentar com a redução da intensidade luminosa (FERRAZ \& SILVA, 2001).

Além da concentração total desses pigmentos, a proporção entre eles e entre as clorofilas $a$ e $b$ muda em função da intensidade luminosa (LEXENGEL \& POGGIANI, 1991). De acordo com isso, folhas adaptadas à sombra possuem uma menor relação clorofila $a / b$ do que as adaptadas ao sol (TAIZ \& ZEIGER, 2002).

$\mathrm{O}$ aumento da proporção de clorofila $b$ é uma característica importante de ambientes sombreados, porque esta capta energia de outros comprimentos de onda e a transfere para a clorofila $a$, que efetivamente atua nas reações fotoquímicas da fotossíntese e representa um mecanismo de adaptação à condição de menor intensidade luminosa (SCALON et al., 2003).

Com o presente trabalho, objetivou-se avaliar o crescimento e o acúmulo de pigmentos fotossintéticos em mudas de maracujá-amarelo sob diferentes níveis de sombreamento.

\section{MATERIAL E MÉTODOS}

O experimento foi conduzido no período de Julho a Setembro de 2005, no Setor de Olericultura do Centro Universitário Luterano de Ji-Paraná (CEULJ/ULBRA), situado no município de Ji-Paraná, localizado na região central do Estado de Rondônia, a 1052'53" de latitude sul e 61'30'45" longitude oeste, com altitude média de $159 \mathrm{~m}$. Segundo classificação de Köppen, o clima da região é caracterizado como $\mathrm{CWa}$ (tropical-quente e úmido). A temperatura média anual oscila em torno de $25^{\circ} \mathrm{C}$, e a precipitação pluviométrica anual de $2.250 \mathrm{~mm}$, com umidade relativa do ar média de $85 \%$.

O material vegetal estudado foi o maracujá-amarelo cujas sementes foram obtidas no comércio local de Ji-Paraná. As mudas foram formadas em saquinhos de polietileno perfurados, de cor preta, com as dimensões de 14 x $22 \mathrm{~cm}$. Cada saquinho foi preenchido com substrato comercial para horticultura marca Plantmax ${ }^{\circledR}$, composto à base de casca de pinus, com as seguintes características: $\mathrm{pH}=5,5-6,0 ;$ relação $\mathrm{C} / \mathrm{N}=22 / 1 \mathrm{e}$ densidade $\left(\mathrm{kg} . \mathrm{L}^{-1}\right)=0,47$. Posteriormente, semearam-se quatro sementes por saquinho, a uma profundidade de aproximadamente $2 \mathrm{~cm}$. Após a emergência foi feito um desbaste, deixando-se somente uma plântula por saquinho. Após o desbaste foram aplicados os tratamentos de sombreamento. Os tratos culturais adotados foram irrigações além de aplicações de inseticida (Decis® $50 \mathrm{CE}$ ) para o controle preventivo de pragas, especialmente coleópteros e pulgões.

Os tratamentos foram em número de quatro, representados pelos seguintes níveis de sombreamento: $0 \%$ (pleno sol); $30 \% ; 50 \%$ e $80 \%$. O sombreamento foi determinado com tela plástica preta conhecida como sombrite. Utilizou-se o delineamento experimental inteiramente casualizado, avaliando-se cinco repetições por tratamento, sendo cada repetição uma muda em um saquinho.

Nos tratamentos em que se aplicou o sombreamento, as plantas foram dispostas sob uma armação de madeira revestida de sombrite na parte superior e nas laterais. Cada armação foi dimensionada em $1,5 \times 1,5 \mathrm{~m}$ na base e $0,75 \mathrm{~m}$ de altura. Para garantir que o sombreamento fosse determinado somente pelo sombrite as armações foram colocadas em uma área aberta.

Após as mudas atingirem uma idade de 90 dias foram realizadas as seguintes análises:

Área foliar: A área foliar foi estimada mediante à comparação da massa seca das folhas com a massa de discos foliares de área conhecida ( $1 \mathrm{~cm}$ de diâmetro).

Altura da planta: Encontrada mediante a obtenção do comprimento do caule. Para isso utilizou-se uma trena e mediuse o comprimento do caule desde o colo até o ápice caulinar.

Comprimento do sistema radicular. Cada muda foi retirada do saquinho, tendo suas raízes lavadas para retirada do substrato. Posteriormente o comprimento do sistema radicular foi obtido tomando-se a medida desde o ápice da raiz principal até a base da planta. 
Massa seca: As folhas, caules e raízes de cada repetição foram colocados em sacos de papel e secados em estufa a $\pm 70{ }^{\circ} \mathrm{C}$, durante 48 horas.

Teores dos pigmentos fotossintéticos: Para a determinação dos teores dos pigmentos fotossintéticos elegeu-se a segunda folha completamente expandida, do ápice para a base, da qual foram retirados 3 discos foliares com $1 \mathrm{~cm}$ de diâmetro, os quais foram imersos em $5 \mathrm{~mL}$ de Dimetilsulfóxido (DMSO), em tubos escuros e vedados. Os tubos foram deixados em bancada por um período de 30 horas. Posteriormente, foram determinadas as leituras da densidade ótica a 470, 663 e $645 \mathrm{~nm}$. Para a obtenção da massa seca, os discos foliares foram, após a extração dos pigmentos, secados por 24 horas em estufa a $\pm 70^{\circ} \mathrm{C}$. Os teores de clorofila e carotenóides foram expressos em $\mathrm{mg} . \mathrm{g}^{-1}$ MS, e calculados de acordo com as equações de Arnon (1949) e Lichtenthaler (1987), conforme segue:

Clor $\boldsymbol{a}=(12,7 . \mathrm{A} 663-2,69 . \mathrm{A} 645 / 1000 \mathrm{MS}) . \mathrm{V}$

Clor $\mathbf{b}=(22,9 . \mathrm{A} 645-4,68 . \mathrm{A} 663 / 1000 \mathrm{MS}) . \mathrm{V}$

Clor. Total $=(20,2 . \mathrm{A} 663-2,69 \cdot \mathrm{A} 645 / 1000 \mathrm{MS}) \cdot \mathrm{V}$

Carotenóides $=$

(1000.A470) - (1,82.Clor.a) - (85,02.Clor.b)/(198).V

Em que: $\mathrm{A} 470$ = absorbância a $470 \mathrm{~nm} ; \mathrm{A} 663=$ absorbância a $663 \mathrm{~nm}$; A645 = absorbância a $645 \mathrm{~nm}$; V = volume da amostra $(\mathrm{mL}) ; \mathrm{MS}=$ massa seca da amostra $(\mathrm{g})$

Os dados obtidos foram submetidos à análise de variância e as médias foram comparadas pelo teste de médias de Tukey a 5\% de probabilidade.

\section{RESULTADOS E DISCUSSÃO}

A área foliar das mudas foi negativamente influenciada pela exposição a pleno sol, sendo a área foliar de $147,63 \mathrm{~cm}^{2}$, registrada no tratamento com $0 \%$ de sombreamento, significativamente menor das obtidas nos tratamentos com sombreamento (Tabela 1). $\mathrm{O}$ aumento em área foliar com o sombreamento é uma das adaptações que permite ao vegetal aumentar rapidamente a superfície fotossintetizante e assegurar um aproveitamento maior das baixas intensidades luminosas (PEDROSO \& VARELA, 1995).

A altura das plantas aumentou progressivamente com a intensidade do sombreamento. Sendo a menor média de $11,1 \mathrm{~cm}$, obtida nas mudas a pleno sol (0\%) e a maior, de $39,4 \mathrm{~cm}$, no tratamento com $80 \%$ de sombreamento. De forma semelhante, Morais et al. (2003) verificaram que o sombreamento induziu maior crescimento em altura, em plantas de café. Conforme Muroya et al. (1997), a altura é um ótimo parâmetro, pois as espécies possuem diferentes padrões de respostas, de acordo com sua capacidade adaptativa às variações na intensidade de luz.
O sistema radicular das plantas do tratamento $0 \%$ apresentou um comprimento de $19,5 \mathrm{~cm}$, significativamente inferior aos obtidos nos tratamentos com 30\%, 50\% e 80\% de sombreamento, os quais foram, respectivamente, 28,$1 ; 26,8 \mathrm{e}$ $30,7 \mathrm{~cm}$ (Tabela 1). O acúmulo de massa seca total nas plantas sob $0 \%$ de sombreamento foi significativamente inferior aos obtidos sob os tratamentos com sombreamento (Tabela 1).

De forma geral, os dados de crescimento apresentados na Tabela 1 evidenciam que a exposição a pleno sol ( $0 \%$ sombramento) foi desfavorável ao crescimento das mudas, sendo a condição de sombreamento de $50 \%$ e $80 \%$ igualmente promissoras no estímulo ao crescimento. Já, o sombreamento de $30 \%$ propiciou um crescimento intermediário ao do tratamento $0 \%$ e os obtidos nos tratamentos $50 \%$ e $80 \%$ de sombreamento. Avaliando o crescimento da parte aérea de plantas de castanha-domaranhão sob sombreamentos de $0 \%, 30 \%$ e $50 \%$, Scalon et al. (2003) concluíram que as mudas crescidas em pleno sol apresentaram maior massa seca, contrastando com um menor acúmulo nas mudas sob 50\% de sombreamento.

Em nosso estudo, o menor crescimento observado nas mudas à ausência de sombreamento pode ser explicado pelo fato de que um excesso de luz, acima da capacidade de utilização pela fotossíntese, pode resultar em uma condição de estresse conhecida como fotoinibição da fotossíntese (BARBER \& ANDERSON, 1992). Diminuindo a eficiência desse processo e conseqüentemente a incorporação de massa pelas plantas. Além de redução na fotossíntese, sob radiação solar excessiva o crescimento pode ter sido prejudicado também por um aumento da taxa respiratória (ROCHA, 2002), diminuindo a fotossíntese líquida e, conseqüentemente, o ganho de biomassa pelas plantas.

Os teores dos pigmentos fotossintéticos estão apresentados na Tabela 2. A maior relação clorofila $a / b$ foi de 3,82 , obtida no tratamento $0 \%$ de sombreamento. Com o aumento do sombreamento, houve um decréscimo dessa relação. Nesse caso, o valor apresentado no tratamento $30 \%$ foi de 1,47 , significativamente inferior ao do tratamento $0 \%$ e superior aos obtidos nos tratamentos $50 \%$ e $80 \%$, os quais foram, respectivamente de 0,76 e 0,61 , não diferindo estatisticamente entre si. Houve uma tendência de aumento na concentração de clorofila total com o aumento do sombreamento. Nesse contexto, a menor concentração de clorofila total foi de $6,3 \mathrm{mg} \cdot \mathrm{g}^{-1} \mathrm{MS}$, obtida igualmente nas plantas sob sombreamento de $0 \%$ e $30 \%$. A maior concentração foi de $8,9 \mathrm{mg} \cdot \mathrm{g}^{-1} \mathrm{MS}$, no tratamento $80 \%$, sendo, este valor significativamente superior ao apresentado no tratamento $50 \%$, que foi de $7,9 \mathrm{mg} \cdot \mathrm{g}^{-1} \mathrm{MS}$. 
TABELA 1 - Área foliar, altura da planta, comprimento do sistema radicular e massa seca total de mudas de maracujazeiro "amarelo" formadas sob diferentes níveis de sombreamento, em Ji-Paraná/RO, de julho a setembro de 2005.

\begin{tabular}{ccccc}
\hline \multirow{2}{*}{ Sombreamento } & Área foliar* & Altura da planta* & Sistema radicular* & Massa seca total* \\
\cline { 2 - 5 } & $\left(\mathbf{c m}^{\mathbf{2}}\right)$ & $11,1 \mathrm{~d}$ & $\mathbf{( c m})$ & $(\mathbf{g})$ \\
\hline $0 \%$ & $147,63 \mathrm{~b}$ ** & $16,4 \mathrm{c}$ & $28,1 \mathrm{a}$ & $0,92 \mathrm{c}$ \\
$30 \%$ & $308,63 \mathrm{a}$ & $24,5 \mathrm{~b}$ & $26,8 \mathrm{a}$ & $1,79 \mathrm{~b}$ \\
$50 \%$ & $316,63 \mathrm{a}$ & $39,4 \mathrm{a}$ & $30,7 \mathrm{a}$ & $1,94 \mathrm{a}$ \\
$80 \%$ & $318,26 \mathrm{a}$ & 6,7 & 9,8 & $1,98 \mathrm{a}$ \\
\hline C.V. $(\%)$ & 6,2 & & & 4,3 \\
\hline
\end{tabular}

*Dados obtidos a partir de mudas com 90 dias a partir da semeadura.

**Letras minúsculas diferentes significam diferenças estatísticas entre os tratamentos, pelo teste de Tukey, ao nível de $5 \%$ de probabilidade.

TABELA 2 - Relação clorofila $a / b$, teor de clorofila total e carotenóides totais na massa seca (MS) de folhas de mudas de maracujazeiro "amarelo" formadas sob diferentes níveis de sombreamento, em Ji-Paraná/RO, de julho a setembro de 2005.

\begin{tabular}{|c|c|c|c|}
\hline \multirow[b]{2}{*}{ Sombreamento } & \multirow[b]{2}{*}{ Clorofila $a / b^{*}$} & Clorofila total* & Carotenóides totais* \\
\hline & & \multicolumn{2}{|c|}{ mg.g $\mathrm{g}^{-1} \mathrm{MS}$} \\
\hline $0 \%$ & $3,82 \mathrm{a}^{* *}$ & $6,30 \mathrm{c}$ & $4,05 \mathrm{a}$ \\
\hline $30 \%$ & $1,47 \mathrm{~b}$ & $6,32 \mathrm{c}$ & $2,87 \mathrm{~b}$ \\
\hline $50 \%$ & $0,76 \mathrm{c}$ & $7,96 \mathrm{~b}$ & $2,26 \mathrm{~b}$ \\
\hline $80 \%$ & $0,61 \mathrm{c}$ & $8,97 \mathrm{a}$ & $2,17 \mathrm{~b}$ \\
\hline C.V. $(\%)$ & 8,6 & 4,2 & 11,5 \\
\hline
\end{tabular}

*Dados obtidos a partir de mudas com 90 dias a partir da semeadura.

**Letras minúsculas diferentes significam diferenças estatísticas entre os tratamentos, pelo teste de Tukey, ao nível de $5 \%$ de probabilidade.

Alguns estudos relatam a observação de teores de clorofilas, por unidade de massa seca, mais elevados em folhas sombreadas em relação àquelas expostas ao sol, e uma razão clorofila $a / b$ maior para folhas de sol (LEI \& LECHOWICZ, 1998; SCALON et al., 2003). Contudo, Almeida et al. (2005) não relataram tal diferença em plantas de Maclura tinctoria (L.) D. Don ex Steud. (Moreira), Hymenaea courbaril L. var. stilbocarpa (Hayne) Lee et Lang. (Jatobá) e Senna macranthera (Collad.) Irwin et Barn. (Fedegoso) expostas a diferentes níveis de sombreamento. Uma das características fotossintéticas das plantas de sol é demonstrar menor quantidade de moléculas de clorofila por cloroplasto, principalmente a clorofila $b$, uma vez que essas plantas não necessitam investir na produção de pigmentos coletores de energia luminosa, em um ambiente saturado por luz (SALISBURY \& ROSS, 1991).

As folhas das plantas mantidas com $0 \%$ de sombreamento apresentaram uma maior concentração de carotenóides totais, $4,05 \mathrm{mg} \cdot \mathrm{g}^{-1}$.MS (Tabela 2). Este valor foi significativamente maior aos obtidos nos tratamentos com sombreamento, cujos valores apresentados não diferiram entre si. A maior concentração de carotenóides em folhas expostas ao pleno sol, pode ser explicada pelo fato de que estes pigmentos estão envolvidos na dissipação do excesso de energia nas folhas (TAIZ \& ZEIGER, 2002).

\section{CONCLUSÕES}

O tratamento com $80 \%$ de sombreamento foi o mais adequado ao crescimento das mudas.

O aumento no nível de sombreamento promoveu uma menor relação clorofila $a / b$, e acréscimos nas concentrações de clorofila total e carotenóides totais.

Para o maracujá, a prática de sombreamento é recomendada durante a fase de formação de mudas. 


\section{REFERÊNCIAS BIBLIOGRÁFICAS}

ALMEIDA, S. M. Z.; SOARES, A. M.; CASTRO, E. M.; VIEIRA, C. V.; GAJEGO, E. B. Alterações morfológicas e alocação de biomassa em plantas jovens de espécies florestais sob diferentes condições de sombreamento. Ciência Rural, Santa Maria, v. 35, n. 1, p. 62-68, 2005.

ARNON, D. I. Copper enzymes in isolated chloroplast: polyphenoloxidase in Beta vulgaris. Plant Physiology, Rockville, v. 24, n. 1, p. 1-15, 1949.

ATROCH, E. M. A. C.; SOARES, A. M.; ALVARENGA, A. A.; CASTRO, E. M. Crescimento, teor de clorofilas, distribuição de biomassa e características anatômicas de plantas jovens de Bauhinia forficata Link submetidas à diferentes condições de sombreamento. Ciência e Agrotecnologia, Lavras, v. 25, n. 4, p. 853-862, 2001.

BARBER, J.; ANDERSON, B. Too much of a good thing: light can be bad for photosynthesis. Trends in Biochemical Sciences, Amsterdam, v. 17, n. 2, p. 61-66, 1992.

ENGEL, V. L. Influência do sombreamento sobre o crescimento de mudas de essências nativas, concentração de clorofila nas folhas e aspectos de anatomia. 1989. $202 \mathrm{f}$. Dissertação (Mestrado em Ciências Florestais) - Escola Superior de Agricultura “Luiz de Queiroz”, Piracicaba, 1989.

FANTI, S. C.; PEREZ, S. C. J. G. A. Influência do sombreamento artificial e da adubação química na produção de mudas de Adenanthera pavonina L. Ciência Florestal, Santa Maria, v. 13, n. 1, p. 49-56, 2003.

FERRAZ, K. K. F.; SILVA, D. M. Avaliação ecofisiológica do crescimento inicial de espécies florestais usadas na recuperação de áreas degradadas: II. Calliandracalothyrsus Meisn. In: CONGRESSO BRASILEIRO DE FISIOLOGIA VEGETAL, 8., 2001, Ilhéus. Anais... Ilhéus: SBFV, 2001. CD-ROM.

LEI, T. T.; LECHOWICZ, M. J. Diverse responses of maple saplings to forest light regimes. Annals of Botany, London, v. 82, n. 1, p. 9-19, 1998.

LEXENGEL, V.; POGGIANI, F. Estudo da concentração de clorofila nas folhas e seu espectro de absorção de luz em função do sombreamento em mudas de quatro espécies florestais nativas. Revista Brasileira de Fisiologia Vegetal, Brasília, v. 3, n. 1, p. 39-45, 1991.
LICHTENTHALER, H. K. Chlorophylls and carotenoids: pigments of photosynthetic biomembranes. In: COLOWICK, S. P.; KAPLAN, N. O. Methods in enzymology. New York: Academic, 1987. p. 350-382.

MELETTI, L. M. M. Maracujá: a qualidade da muda é essencial. O Agronômico, Campinas, v. 46, n. 1/3, p. 9-12, 1994.

MELETTI, L. M. M. Propagação de frutíferas tropicais. Guaíba: Agropecuária, 2000. 239 p.

MORAIS, H.; MARUR, C. J.; CARAMORI, P. H.; RIBEIRO, A. M. A.; GOMES, J. C. Características fisiológicas e de crescimento de cafeeiro sombreado com guandu e cultivado a pleno sol. Pesquisa Agropecuária Brasileira, Brasília, v. 38, n. 10, p. 1131-1137, 2003.

MUROYA, K.; VARELA, V. P.; CAMPOS, M. A. A. Análise de crescimento de mudas de jacareúba (Calophyllum angulare - Guttiferae) cultivadas em condições de viveiro. Acta Amazonica, Manaus, v. 27, n. 3, p. 197-212, 1997.

PAIVA, C. L.; GUIMARÃES, R. J.; SOUZA, C. A. S. Influência de diferentes níveis de sombreamento sobre o crescimento de mudas de cafeeiro (Coffea arabica L.). Ciência e Agrotecnologia, Lavras, v. 27, n. 1, p. 134-140, 2003.

PEDROSO, S. G.; VARELA, V. P. Efeito do sombreamento no crescimento de mudas de Sumaúma (Ceiba pentandra (L.) Gaertn). Revista Brasileira de Sementes, Brasília, v. 17, n. 1, p. 47-51, 1995.

ROCHA, P. K. Desenvolvimento de bromélias cultivadas em ambientes protegidos com diferentes alturas e níveis de sombreamento. 2002. 84 f. Dissertação (Mestrado em Agronomia) - Escola Superior de Agricultura "Luiz de Queiroz", Piracicaba, 2002.

SALISBURY, F. B.; ROSS, C. W. Plant physiology. 3. ed. Belmont: Wadsworth, 1991. 692 p.

SCALON, S. P. Q.; MUSSURY, R. M.; RIGONI, M. R.; SCALON FILHO, R. Crescimento inicial de mudas de Bombacopsis glabra (Pasq.) A. Robyns sob condição de sombreamento. Revista Árvore, Viçosa, v. 27, n. 6, p. 753758, 2003.

TAIZ, L.; ZEIGER, E. Plant Physiology. 3. ed. Massachussetts: Sinauer Associates, 2002. 690 p. 